or white matter migration lines. (Boronat S, Caruso P, Auladell M, Van Eeghen A, Thiele EA. Arachnoid cysts in tuberous sclerosis complex. Brain Dev 2014 Oct;36(9):801-6).

COMMENTARY. Arachnoid cysts may be part of the clinical spectrum of TSC. They originate from the cranial leptomeninges and dysfunction of the neural crest. Most are sporadic but some are familial, suggesting a genetic factor. The location is predominantly in the left temporal fossa but some are bilateral. Arachnoid cysts are also reported in neurofibromatosis type 1 [1], and Sturge-Weber syndrome [2].

\title{
References.
}

1. Boltshauser E, et al. Neurofibromatosis. 1989;2(5-6):274-7.

2. Ergun R, et al. Acta Neurochir (Wien). 2007 Aug;149(8):829-30.

\section{RIPPLES AND FAST RIPPLES AS MARKERS FOR EPILEPTOGENIC ZONE IN TS COMPLEX}

Investigators from the Hospital for Sick Children, Toronto, Canada, and Okayama University Hospital, Japan, analyzed the high occurrence rate (OR) of interictal high frequency oscillations (HFOs) at $80-200 \mathrm{~Hz}$ (ripples) and $>200 \mathrm{~Hz}$ (fast ripples, FRs). The resection ratios of high-OR ripples and high-OR FRs showed significant correlations with seizure outcome ( $\mathrm{p}=0.038$ and 0.048 , respectively). Multiple extensive zones with high-OR HFOs suggest a complex and widespread epileptic network in TSC. In patients with drug-resistant epilepsy, resection of cortex with both interictal high-OR ripples and high-OR FRs on IVEEG correlated with a good seizure outcome. (Okanishi T, Akiyama $\mathrm{T}$, Tanaka $\mathrm{S}$, et al. Interictal high frequency oscillations correlating with seizure outcome in patients with widespread epileptic networks in tuberous sclerosis complex. Epilepsia 2014 Oct;55(10):1602-10).

COMMENTARY. A previous study by investigators at the Royal Children's Hospital, Melbourne, Australia, found interictal FR involved tubers in TSC more commonly than perituberal cortex but were not associated with electroclinically distinct seizures (EDS). Tubers play a greater role in seizure genesis than perituberal cortex, suggesting that tuberectomy may be a sufficient surgical approach in a number of TSC patients with seizures. Ictal fast rhythms at seizure onset were confined to tubers in $73 \%$ and involved tuber with perituberal cortex in $27 \%$ [1].

In a subset of TSC patients, the distribution of the epileptogenic zone propagates with time from a single focus at the onset of seizures to bilateral and multiple foci. The laterality of spikes during REM sleep on video EEG monitoring correlates with the epileptogenic hemisphere. The video EEG and MEG are helpful in identifying the epileptogenic zone among multiple cortical tubers [2].

\section{References.}

1. Mohamed AR, et al. Neurology. 2012 Dec 4;79(23):2249-57.

2. Okanisni T, et al. No To Hattatsu. 2014 Jul;46(4):257-63. 